\title{
RP-HPLC-UV Method for Simultaneous Quantification of Second Generation Non-Steroidal Antiandrogens Along with their Active Metabolites in Mice Plasma: Application to a Pharmacokinetic Study
}

\author{
Authors \\ Ashok Zakkula, Vinay Kiran, Umesh Todmal, Suresh P Sulochana, Ramesh Mullangi
}

Affiliation

Drug Metabolism and Pharmacokinetics, Jubilant Biosys Ltd, Industrial Suburb, Yeshwanthpur, Bangalore, India

\author{
Key words \\ $\mathrm{N}$-desmethylenzalutamide, HPLC, method validation, \\ mice plasma, pharmacokinetics

\section{Bibliography} \\ DOI https://doi.org/10.1055/a-0790-8309 \\ Published online: 10.12 .2018 \\ Drug Res 2019; 69: 537-544 \\ (c) Georg Thieme Verlag KG Stuttgart · New York \\ ISSN 2194-9379

\section{Correspondence} \\ Dr. Ramesh Mullangi \\ Jubilant Biosys \\ Industrial Suburb \\ Yeshwanthpur \\ Bangalore-560020 \\ Tel.: + 91/80/66628 339 \\ mullangi.ramesh@jubilantinnovation.com
}

apalutamide, darolutamide, ORM-15341, enzalutamide,

\begin{abstract}
A simple, specific and reproducible high-performance liquid chromatography (HPLC) assay method has been developed and validated for the quantitation of second generation antiandrogens and their active metabolites namely apalutamide, enzalutamide, $\mathrm{N}$-desmethylenzalutamide (active metabolite of enzalutamide), darolutamide and ORM-15341 (active metabolite of darolutamide) in mice plasma. The method involves extraction of apalutamide, enzalutamide, $\mathrm{N}$-desmethylenzalutamide, darolutamide and ORM-15341 along with internal standard (IS) from $100 \mu \mathrm{L}$ mice plasma through a simple protein precipitation process. The chromatographic analysis was performed on a Waters Alliance HPLC system using a gradient mobile phase (comprising $10 \mathrm{mM}$ ammonium acetate and acetonitrile in a flow-gradient) and X-Terra Phenyl column. The UV detection wave length was set at $\lambda_{\max } 250 \mathrm{~nm}$. Apalutamide, enzalutamide, $N$-desmethylenzalutamide, darolutamide and ORM-15341 and the IS eluted at 13.6, 11.4, 9.68, 6.11, 6.93 and $4.69 \mathrm{~min}$, respectively with a total run time of $15 \mathrm{~min}$. Method validation was performed as per regulatory guidelines and the results met the acceptance criteria. The calibration curve was linear over a concentration range of $209-5215 \mathrm{ng} / \mathrm{mL}\left(r^{2}=0.998\right)$. The intra- and inter-day precisions were in the range of $0.56-13.5$ and $1.04-13.9 \%$, respectively. The validated HPLC method was successfully applied to a pharmacokinetic study in mice.
\end{abstract}

\section{Introduction}

Despite therapeutic advances, prostate adenocarcinoma is the highly prevalent cancer in men and responsible for $20 \%$ of cancer related deaths in the Western world [1]. Initial approach to cure the localized prostate cancer is through radiation therapy or surgical castration or treatment with first-generation antiandrogens namely flutamide, nilutamide, bicalutamide [2]. In spite of initial response, majority of the patients develop a most aggressive form of disease called metastatic castration-resistant prostate cancer (mCRPC) that is associated with tumor progression and survival is less than 2 years [3]. Consequently, in recent years, new therapy options for mCRPC with different mechanisms of action have become available like targeting androgen receptor signaling such as CYP17A1 inhibitor (abiraterone acetate) [4] and a second-generation antiandrogens namely enzalutamide ( $\triangleright$ Fig. 1a1), apalutamide ( $\mathbf{F i g . ~ 1 b ) ~ a n d ~}$ darolutamide ( Fig. 1c) [5-7]. Treatment with these drugs showed improved overall survival and quality of life in mCRPC patients.

Apalutamide (ARN-509 or JNJ-56021927; - Fig. 1b) is having similar in vitro activity to enzalutamide ( $>$ Fig. 1a1) but with greater in vivo activity in CRPC xenograft models [8]. Apalutamide ( $\mathbf{F i g . ~ 1 b ) ~}$ weakly binds to $G A B A_{A}$ receptors and poorly penetrates through blood-brain-barrier suggesting that the chances of developing seizures may be less when compared with enzalutamide ( $\triangleright$ Fig. 1a1) [9]. Recently FDA approved apalutamide ( $\mathbf{F i g}$. 1b) based on the Phase-3 SPARTAN trial in which apalutamide ( $>$ Fig. $\mathbf{1 b}$ ) reduced the risk of metastasis or death by $72 \%$ in patients with non-mCRPC [10]. Enzalutamide (Xtandi ${ }^{\circledR}$; $>$ Fig. 1a1) was approved for the treatment of mCRPC in 2012 [5, 11]. Enzalutamide ( Fig. 1a1) is metabolized by CYP3A4 and 2C8 to produce an active circulatory metabolite, $\mathrm{N}$-desmethylenzalutamide ( $\triangleright$ Fig. 1a2), which has similar in vitro 


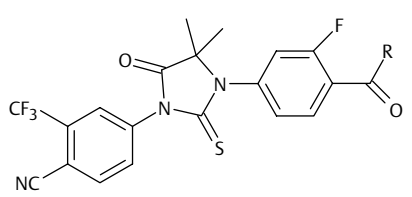

Enzalutamide, $\mathrm{R}=\mathrm{NHCH}_{3}$ $\mathrm{N}$-Desmethylenzalutamide, $\mathrm{R}=\mathrm{NH}_{2}$

c<smiles>CC(O)c1cc(C(=O)N[C@@H](C)Cn2ccc(-c3ccc(C#N)c(Cl)c3)n2)n[nH]1</smiles>

Darolutamide b<smiles>CNC(=O)c1ccc(N2C(=S)N(c3cnc(C#N)c(C(F)(F)F)c3)C(=O)C23CCC3)cc1F</smiles>

Apalutamide

d<smiles>CC(=O)c1cc(C(=O)N[C@@H](C)Cn2ccc(-c3ccc(C#N)c(Cl)c3)n2)n[nH]1</smiles>

ORM-15341

Fig. 1 Structural representation of enzalutamide a1, $\mathbf{N}$-desmethylenzalutamide $\mathbf{a 2}$, apalutamide $\mathbf{b}$, darolutamide $\mathbf{c}$ and ORM-15341 d.

potency to enzalutamide [12,13]. Darolutamide (ODM-201; > Fig. 1c) is an equi-mixture of 2 pharmacologically active diastereomers namely ORM-16497 and ORM-16555 (structures not shown). Darolutamide ( $\triangleright$ Fig. 1c) undergoes extensive Phase-I metabolism and produces active circulatory metabolite i.e., ORM-15341 (• Fig. 1d). ORM-16497 (structure not shown), ORM-16555 (structure not shown) and ORM-15341 ( $>$ Fig. 1d) exert complete antagonistic effect on bicalutamide, hydroxyflutamide, enzalutamide ( and ARN-509 mutants [14, 15]. Unlike enzalutamide ( Fig. 1a1) and apalutamide ( $\triangleright$ Fig. 1b), penetration of darolutamide ( $\triangleright$ Fig. $1 \mathbf{1 c}$ ) and ORM-15341 ( Fig. 1d) into brain is negligible (in preclinical species) suggests that low risk of causing seizures in patients [7]. It was reported that ORM-15341 plasma concentrations were higher than sum of ORM-16497 and ORM-16555 (structures not shown) plasma concentrations in cancer patients [16]. We have also seen the similar trend in mice post-administration of darolutamide (•Fig. 1c) orally and intravenously $[17,18]$. Currently Phase-3 clinical trials are being conducted with darolutamide ( $\mathbf{F i g} .1 \mathrm{1c}$ ) in non-mCRPC patients globally [7].

Literature search revealed that most of the bioanalytical methods published for the quantification of second generation antiandrogens were LC-MS/MS based. Quantification of apalutamide ( $\triangleright$ Fig. 1b) alone [19] or along with other antiandrogens was reported by us in mice plasma [18]. LC-MS/MS based bioanalytical methods were reported for quantification of enzalutamide ( alone [20] or along with its metabolites [21,22] and other antiandrogens $[18,23,24]$ or anticancer drugs [25] in various biological matrices (preclinical species plasma/tissues and human plasma). Similarly, darolutamide ( $\triangleright$ Fig. 1c) and ORM-15341 ( Fig. 1d) quantification in mice plasma was reported post-administration of darolutamide [17] and along with other second-generation non-steroidal antiandrogens [18] using conventional achiral columns on LC-MS/MS. Apart from these achiral methods, 2 chiral LC-MS/MS methods for quantification darolutamide ( $\mathbf{F i g . 1 C}$ ) diastereomers alone [26] or along with its metabolite i. e., ORM-15341 (•Fig. 1d)
[27] were reported in recent times. Of late, we have reported dried blood spot (DBS) method for simultaneous quantification of enzalutamide ( $\triangleright$ Fig. 1a1), N-desmethylenzalutamide ( Fig. 1a2), daro-

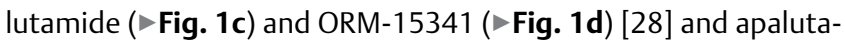
mide ( $\triangleright$ Fig. 1b) [29] in mice blood shown the validated methods application in a mice pharmacokinetic study.

LC-MS/MS is an expensive technique, which requires high investment in both equipment purchase and maintenance. Many laboratories and most of the hospitals will have HPLC systems for routine application. Only one method has been reported for quantification of second generation antiandrogens. Recently, a HPLC-UV method has been published for the quantification of enzalutamide ( Fig. 1a1) and its active metabolite, $N$-desmethylenzalutamide ( Fig. 1a2) trough concentration in plasma collected from mCRPC patients [30]. In this paper an isocratic mobile phase was used to resolve enzalutamide ( $>$ Fig. 1a1) and $N$-desmethylenzalutamide ( Fig. 1a2) along with nilutamide (structure not shown; internal standard; IS) on $C_{18}$ column within 9 min run time. We tried this method for the quantification of other second generation antiandrogens and found that apalutamide ( $\vee$ Fig. 1b) did not elute under these conditions, however darolutamide ( Fig. 1c) and ORM-15341 ( $\triangleright$ Fig. 1d) eluted very early (within $2.5 \mathrm{~min}$ ) and there is great chance that endogenous interference will mask these 2 analytes. Hence, we felt that there is a great need to develop and validate a generic HPLC method for quantification of apalutamide ( $>$ Fig. 1b), darolutamide ( $\triangleright$ Fig. 1c), ORM-15341 ( Fig. 1d), enzalutamide ( Fig. 1a1), N-desmethylenzalutamide ( $>$ Fig. 1a2) in mice plasma, which will be a valuable to support pharmacokinetic studies and clinical setup. The objective of the present study was to develop and validate a simple, specific, sensitive and reproducible HPLC method for quantitation of apalutamide ( Fig. 1b), darolutamide

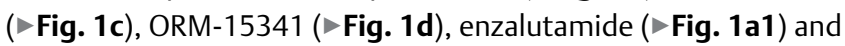
$\mathrm{N}$-desmethylenzalutamide ( $>$ Fig. 1a2) in mice plasma. The validated method was successfully applied to a pharmacokinetic study in mice. 


\section{Materials and Methods}

\section{Chemicals and reagents}

Darolutamide (purity:>97\%) was obtained from Angene International Limited, China. Enzalutamide (purity:>98.3\%) and $\mathrm{N}$-desmethylenzalutamide (purity: >99.6\%) were purchased from BioOrganics, Bangalore, India. ORM-15341 (purity: 99.4\%) and apalutamide (purity: $99.5 \%$ ) were synthesized by the Medicinal Chemistry Group, Jubilant Biosys, Bangalore, India using literature information [31, 32] and the compounds were characterized using chromatographic (HPLC, LC-MS/MS) and spectral techniques (IR, UV, Mass, ${ }^{1} \mathrm{H}$ and ${ }^{13} \mathrm{C}-\mathrm{NMR}$ ) by the Analytical Research Group, Jubilant Biosys. Phenacetin (purity; >99\%) was purchased from SigmaAldrich (St Louis, MO, USA). HPLC grade acetonitrile and methanol were purchased from Rankem, Ranbaxy Fine Chemicals Limited, New Delhi, India. Analytical grade formic acid was purchased from S.D Fine Chemicals, Mumbai, India. All other chemicals and reagents were of analytical grade and used without further purification. Microcaps ${ }^{\circledR}$ Disposable Micropipettes $(50 \mu \mathrm{L}$, catalogue number: 1-000-0500) were purchased from Drummond Scientific Company, USA. The control mice $\mathrm{K}_{2}$. EDTA plasma sample was procured from Animal House, Jubilant Biosys.

\section{HPLC operating conditions}

Apalutamide, enzalutamide, $N$-desmethylenzalutamide, darolutamide and ORM-15341 and the IS were assayed using Waters 2695 Alliance HPLC system (Waters, Milford, USA) equipped with performance PLUS inline degasser along with an auto-sampler and photo diode array (PDA) detector set at $\lambda_{\max } 250 \mathrm{~nm}$ for quantitation of the analytes and the IS. The chromatographic separation apalutamide, darolutamide, ORM-15341, enzalutamide, $N$-desmethylenzalutamide and the IS in processed samples was achieved on a X-Terra Phenyl column $(150 \times 3.9 \mathrm{~mm}, 5 \mu$; Waters Corporation, Milford, USA) maintained at $40 \pm 1{ }^{\circ} \mathrm{C}$. The binary mobile phase system consisted of reservoir $\mathrm{A}(10 \mathrm{mM}$ ammonium acetate, $\mathrm{pH}: 4.8)$ and reservoir $B$ (acetonitrile) were run as per the flow regulated gradient program given in $>$ Table 1 . The injection volume was $10 \mu \mathrm{L}$.

\section{Preparation of standard solutions}

Primary stock solutions of apalutamide, darolutamide, ORM15341, enzalutamide, $N$-desmethylenzalutamide for preparation of calibration curve (CC) and quality control (QC) samples were prepared from separate weighing. Individual primary stock solution of all the analytes at $200 \mu \mathrm{g} / \mathrm{mL}$ was prepared in DMSO:methanol $(0.2: 99.8, v / v)$. Similarly the primary stock solution of the IS $(1000 \mu \mathrm{g} / \mathrm{mL})$ was prepared in methanol. The stock solutions of apalutamide, darolutamide, ORM-15341, enzalutamide, $N$-desmethylenzalutamide and the IS were stored at $2-8^{\circ} \mathrm{C}$, which were found to be stable for 45 days and successively diluted with DMSO:methanol (0.2:99.8, v/v) to prepare appropriate working solutions to perform calibration curve (CC). Another set of working stock solutions of apalutamide, darolutamide, ORM-15341, enzalutamide, $N$-desmethylenzalutamide were made in DMSO:methanol $(0.2: 99.8, \mathrm{v} / \mathrm{v})$ (from primary stock) at appropriate dilutions for preparation of QC samples. A working IS solution $(500 \mathrm{ng} / \mathrm{mL})$ was prepared in methanol. Working stock solutions were stored approximately at $4^{\circ} \mathrm{C}$ for 30 days.
- Table 1 HPLC flow-binary gradient operated-time program used for simultaneous quantitation of apalutamide, darolutamide, ORM-15341, enzalutamide and $\mathrm{N}$-desmethylenzalutamide.

\begin{tabular}{|l|l|l|l|}
\hline $\begin{array}{l}\text { Time } \\
(\mathbf{m i n})\end{array}$ & $\begin{array}{l}\text { Flow rate } \\
(\mathbf{m L} / \mathbf{m i n})\end{array}$ & $\begin{array}{l}\text { Mobile phase A } \\
\left(\mathbf{N H}_{\mathbf{4}} \mathbf{A c}\right) \mathbf{( \% )}\end{array}$ & $\begin{array}{l}\text { Mobile phase B } \\
\left(\mathbf{C H}_{\mathbf{3}} \mathbf{C N}\right) \mathbf{( \% )}\end{array}$ \\
\hline 0.00 & 0.20 & 70 & 30 \\
\hline 2.00 & 0.40 & 70 & 30 \\
\hline 4.00 & 0.80 & 60 & 40 \\
\hline 8.00 & 1.20 & 60 & 40 \\
\hline 15.0 & 1.20 & 70 & 30 \\
\hline
\end{tabular}

\section{Preparation of calibration curve standards and quality control samples}

Calibration samples were prepared by spiking $90 \mu \mathrm{L}$ of blank mice plasma with the mixed working solution of analytes $(10 \mu \mathrm{L})$ on the day of analysis. Calibration curve standard consists of a set of 8 nonzero concentrations (209, 417, 1043, 1617, 2086, 3129, 4120 and $5125 \mathrm{ng} / \mathrm{mL}$ ) for all the analytes was prepared. Samples for the determination of precision and accuracy were prepared by spiking blank mice plasma in bulk with mixed working stock solution of analytes at appropriate concentrations and $100 \mu \mathrm{L}$ aliquots were distributed into different tubes. The QCs prepared for each analyte are: $209 \mathrm{ng} / \mathrm{mL}$ (lower limit of quantification quality control; LLOQ QC), $626 \mathrm{ng} / \mathrm{mL}$ (low quality control; LQC), $2503 \mathrm{ng} / \mathrm{mL}$ (medium quality control; MQC) and $4172 \mathrm{ng} / \mathrm{mL}$ (high quality control; HQC). All the samples were stored together at $-80 \pm 10^{\circ} \mathrm{C}$ until analysis.

\section{Sample preparation}

To an aliquot of $100 \mu \mathrm{L}$ plasma sample, $200 \mu \mathrm{L}$ of acetonitrile enriched with IS $(500 \mathrm{ng} / \mathrm{mL})$ was added and vortex mixed for $3 \mathrm{~min}$; followed by centrifugation for $5 \mathrm{~min}$ at $20,817 \mathrm{~g}$ in a refrigerated centrifuge (Eppendorf $5424 \mathrm{R}$ ) maintained at $5{ }^{\circ} \mathrm{C}$ to precipitate protein matrix and particulate matter. Clear supernatant $(100 \mu \mathrm{L})$ was transferred into a vial and $10 \mu \mathrm{L}$ was injected onto HPLC system.

\section{Validation procedures}

A full validation according to the US FDA guidance was performed for the quantitation of apalutamide, darolutamide, ORM-15341, enzalutamide and $\mathrm{N}$-desmethylenzalutamide in mice plasma [33].

\section{Selectivity}

Selectivity of the method was determined by determining the presence of interfering peaks from 6 individual drug-free mice plasma samples at the retention times of apalutamide, darolutamide, ORM-15341, enzalutamide, $\mathrm{N}$-desmethylenzalutamide and the IS.

\section{Limit of quantification and carry over}

The LLOQ was determined as the concentration that has a precision of $<20 \%$ of the relative standard deviation (\%RSD) and accuracy between $80-120 \%$ of the theoretical value. The auto-injector carryover was determined by injecting the highest calibration standard, followed by injection of blank samples. The response of the blanks was then compared to that of the LLOQ.

\section{Recovery}

The recovery of apalutamide, darolutamide, ORM-15341, enzalutamide, $\mathrm{N}$-desmethylenzalutamide and the IS extraction from mice 
plasma was determined by comparing the response of each analyte extracted (using simple protein precipitation by adding acetonitrile) from replicate $Q C$ samples $(n=6)$ with the response of analyte from neat standards at equivalent concentrations. Recovery of apalutamide, darolutamide, ORM-15341, enzalutamide and $\mathrm{N}$-desmethylenzalutamide was determined at LQC $(626 \mathrm{ng} / \mathrm{mL})$, MQC $(2503 \mathrm{ng} / \mathrm{mL})$ and HQC (4172 ng/mL) concentrations. Recovery of the IS was determined at a single concentration of $500 \mathrm{ng} / \mathrm{mL}$.

\section{Calibration curve}

Calibration samples (for all the analytes) were prepared on each validation day. Peak area ratios of each analyte to that of the IS were used for all calculations. A least squares linear regression $\left(1 / X^{2}\right.$ weighting factor) of 8 non-zero samples was used to define the calibration curve.

\section{Precision and accuracy}

The precision and accuracy of the method were evaluated by measuring the 4 QC samples (LLOQ QC, LQC, MQC and HQC), which were prepared on each validation day ( $n=6$ each). Inter-day precision was assessed on 4 separate days. Inter- and intra-day precisions were determined by calculating \%RSD that should be $\leq 15 \%$ for all the QC levels except for LLOQ QC where it should be $\leq 20 \%$. The inter- and intra-day accuracy expressed as percent relative error (\%RE) was calculated by comparing the measured concentration with the nominal value and deviation was limited within $\pm 15 \%$ except for LLOQ QC where it should be $\leq 20 \%$.

\section{Stability}

The stability of apalutamide, darolutamide, ORM-15341, enzalutamide and $\mathrm{N}$-desmethylenzalutamide was assessed at LQC and HQC levels in 6 replicates under all storage conditions. Freeze-thaw stability was performed following 3 freeze-thaw cycles was evaluated (plasma samples were stored in $-80 \pm 10^{\circ} \mathrm{C}$ between freeze/ thaw cycles). Short-term temperature stability was assessed by analyzing samples that had been kept at ambient temperature $\left(25 \pm 1^{\circ} \mathrm{C}\right)$ for $6 \mathrm{~h}$. Long-term stability was performed by analyzing samples that had been stored at $-80 \pm 10^{\circ} \mathrm{C}$ for 30 days. The stability of apalutamide, darolutamide, ORM-15341, enzalutamide, $\mathrm{N}$-desmethylenzalutamide and the IS in the injection solvent was determined periodically by injecting replicate preparations of processed plasma samples for up to $24 \mathrm{~h}$ (in the auto-sampler at $5^{\circ} \mathrm{C}$ ) after the initial injection.

\section{Dilution effect}

To evaluate the effect of dilution over the calibration range, the accuracy and precision of dilution control samples at 25,625 ng/ $\mathrm{mL}(\mathrm{n}=6 ; 5$ times of the ULOQ) were assessed by performing a 10-fold dilution.

\section{Pharmacokinetic study in mice}

Animal experiments were approved by Institutional Animal Ethical Committee (IAEC/JDC/2017/135). Male BalbC mice ( $\mathrm{n}=12 ; 27-29 \mathrm{~g}$ weight) were procured from Vivo Biotech, Hyderabad, India. The animals were housed in Jubilant Biosys animal house facility in a temperature $\left(22 \pm 2{ }^{\circ} \mathrm{C}\right)$ and humidity $(30-70 \%)$ controlled room (15 air changes/h) with a 12:12 h light:dark cycles, had free access to rodent feed (Altromin Spezialfutter GmbH \& Co. KG., Im Seelenkamp 20, D-32791, Lage, Germany) and water for one week before using for experimental purpose. Following $4 \mathrm{~h}$ fast (during the fasting period animals had free access to water) mice received apalutamide, darolutamide and enzalutamide as a cassette dose orally at $20 \mathrm{mg} / \mathrm{kg}$ [suspension formulation prepared using $0.1 \%$ Tween80 with methyl cellulose $(0.5 \%$ in water); strength: $2.0 \mathrm{mg} / \mathrm{mL}$; dose volume: $10 \mathrm{~mL} / \mathrm{kg}$ ]. Post-dosing blood samples $(200 \mu \mathrm{L})$ were collected into polypropylene tubes containing $\mathrm{K}_{2}$. EDTA solution as an anti-coagulant at $0.25,0.5,1,2,4,6,8,12,24,48,72$ and $96 \mathrm{~h}$ (sparse sampling protocol was adopted during blood collection and at each time point blood was collected from 3 mice). Plasma was harvested by centrifuging the blood using Biofuge (Hereaus, Germany) at $1760 \mathrm{~g}$ for $5 \mathrm{~min}$ and stored frozen at $-80 \pm 10^{\circ} \mathrm{C}$ until analysis. Animals were allowed access to feed $2 \mathrm{~h}$ post-dosing.

Thawed plasma sample were processed as mentioned in sample preparation section. Along with plasma samples, QC samples at low, medium and high concentration (made in blank plasma) were assayed in duplicate and were distributed among unknown samples in the analytical run. The criteria for acceptance of the analytical runs encompassed the following: (i) $67 \%$ of the QC samples accuracy must be within $85-115 \%$ of the nominal concentration (ii) not less than $50 \%$ at each QC concentration level must meet the acceptance criteria [33]. The pharmacokinetic parameters were calculated by using Phoenix WinNonlin software (version 8.0; Pharsight Corporation, Mountain View, CA).

\section{Results and Discussion}

\section{Chromatographic conditions}

Selection of chromatographic conditions for the proposed method was optimized to suit the preclinical and clinical pharmacokinetic studies. As briefed in the introduction section we tried the enzalutamide HPLC method reported by Puszkiel et al. [30] for the quantification of other second generation antiandrogens and found that apalutamide (structurally very close to enzalutamide as shown in - Fig. 1a1) did not elute under these conditions, however darolutamide and ORM-15341 eluted very early (within $2.5 \mathrm{~min}$ ) and in comparison to our results as demonstrated in $\mathbf{F i g} . \mathbf{2}$ it is evident that endogenous interference will mask these 2 analytes. Hence we tried different mobile phases comprising several combinations of buffers (e.g., phosphate buffer and ammonium acetate buffer) and organic solvents (acetonitrile and methanol) along with altered flow-rates (in the range of $0.60-1.20 \mathrm{~mL} / \mathrm{min}$ ) were tested to optimize for an effective chromatographic resolution of apalutamide, darolutamide, ORM-15341, enzalutamide, $\mathrm{N}$-desmethylenzalutamide and the IS (data not shown). The best resolution of peaks was achieved with a mobile phase comprising $10 \mathrm{mM}$ ammonium acetate $(\mathrm{pH} 4.8)$ :acetonitrile in a flow operated binary gradient mode on an X-Terra phenyl column.

\section{Recovery}

The recovery (mean \pm S.D) for apalutamide, darolutamide, ORM15341, enzalutamide and $N$-desmethylenzalutamide at LQC, MQC and HQC and for the IS at single concentration is shown in > Table 2. 


\section{Selectivity}

As shown in > Fig. 2 no interferences in the blank mice plasma traces were found from endogenous components in drug-free mice plasma at the retention times of the apalutamide, darolutamide, ORM-15341, enzalutamide, $\mathrm{N}$-desmethylenzalutamide and the IS indicating that the method is selective. Apalutamide, enzalutamide, $N$-desmethylenzalutamide, darolutamide and ORM-15341 and the IS eluted at 13.6, $11.4,9.68,6.11,6.93$ and $4.69 \mathrm{~min}$, respectively.

\section{Sensitivity and carry over}

The lowest limit of reliable quantification for each analyte was set at the concentration of the LLOQ. The precision (\%RSD) and accuracy (\%RE) at LLOQ concentration were found to be 3.40 and $105 \%$ for apalutamide, 8.88 and $87.7 \%$ for darolutamide, 1.13 and $101 \%$ for ORM-15341, 4.06 and $102 \%$ for enzalutamide and 3.40 and $98.8 \%$ for $\mathrm{N}$-desmethylenzalutamide. There was no carry-over produced by the highest calibration sample on the following injected mice plasma extracted sample for all the analytes.

\section{Calibration curve}

The plasma calibration curve was constructed using 8 calibration standards (viz., $209-5215 \mathrm{ng} / \mathrm{mL}$ ). The calibration standard curve had a reliable reproducibility over the standard concentrations across the calibration range. Calibration curve was prepared by determining the best fit of peak-area ratios (peak area analyte/peak area of the IS) vs. concentration, and fitted to the $y=m x+c$ using weighing factor $\left(1 / X^{2}\right)$. The average regression $(n=4)$ was found to be $>0.998$. The lowest concentration with the RSD $\leq 20 \%$ was taken as LLOQ and was found to be $209 \mathrm{ng} / \mathrm{mL}$. The accuracy observed for the mean of back-calculated concentrations for 4 calibration curves was within $87.3-108 \%$; while the precision ( $\%$ RE) values ranged from $0.05-12.2 \%$ for all the analytes.

\section{Accuracy and precision}

Accuracy and precision data for intra- and inter-day mice plasma samples are presented in $\mathbf{r}$ Table $\mathbf{2}$. The assay values on both the occasions (intra- and inter-day) were found to be within the accepted variable limits. The data show that the method possesses adequate accuracy and repeatability for analyzing apalutamide, darolutamide, ORM-15341, enzalutamide and N-desmethylenzalutamide in mice plasma samples.

\section{Stability}

- Table 3 summarizes the results of stability studies conducted for apalutamide, darolutamide, ORM-15341, enzalutamide and $\mathrm{N}$-desmethylenzalutamide in mice plasma. The measured concentrations for these analytes at 626 and $4172 \mathrm{ng} / \mathrm{mL}$ samples deviated within $\pm 15 \%$ of the nominal concentrations in a battery of stability tests viz., in-injector ( $24 \mathrm{~h})$, bench-top $(6 \mathrm{~h})$, repeated 3 freeze/thaw cycles and freezer stability at $-80 \pm 10{ }^{\circ} \mathrm{C}$ for at least for 30 days ( $\triangleright$ Table 3 ). The results were found to be within the assay variability limits during the entire process and demonstrated that apalutamide, darolutamide, ORM-15341, enzalutamide and $\mathrm{N}$-desmethylenzalutamide can be stored under tested conditions without compromising the integrity of samples.

\section{Dilution effect}

The dilution integrity was confirmed for QC samples that exceeded the upper limit of standard calibration curve. The results showed that the accuracy (within $7.5 \%$ ) and precision ( $\leq 8.7 \%$ ) for $10 x$ diluted test samples (for all the analytes), which show the ability to dilute samples up to a dilution factor of 10 in a linear fashion.

\section{Pharmacokinetic study}

Following oral administration of apalutamide, enzalutamide and darolutamide as a cassette dosing to mice, enzalutamide is quantifiable up to $48 \mathrm{~h}$ as illustrated in $>$ Fig. 3i/1, N-desmethylenzalutamide (released from enzalutamide) is quantifiable up to $96 \mathrm{~h}$ as shown in > Fig. 3i/1. More detailed information about plasma concentrations of enzalutamide and $\mathrm{N}$-desmethylenzalutamide from $\mathbf{0}-24 \mathrm{~h}$ is presented in $\mathbf{F i g . ~} \mathbf{3 i} / \mathbf{2}$. The apalutamide is quantifiable up to 48 h, as illustrated in > Fig. 3ii. Daroluatmide and ORM-15341

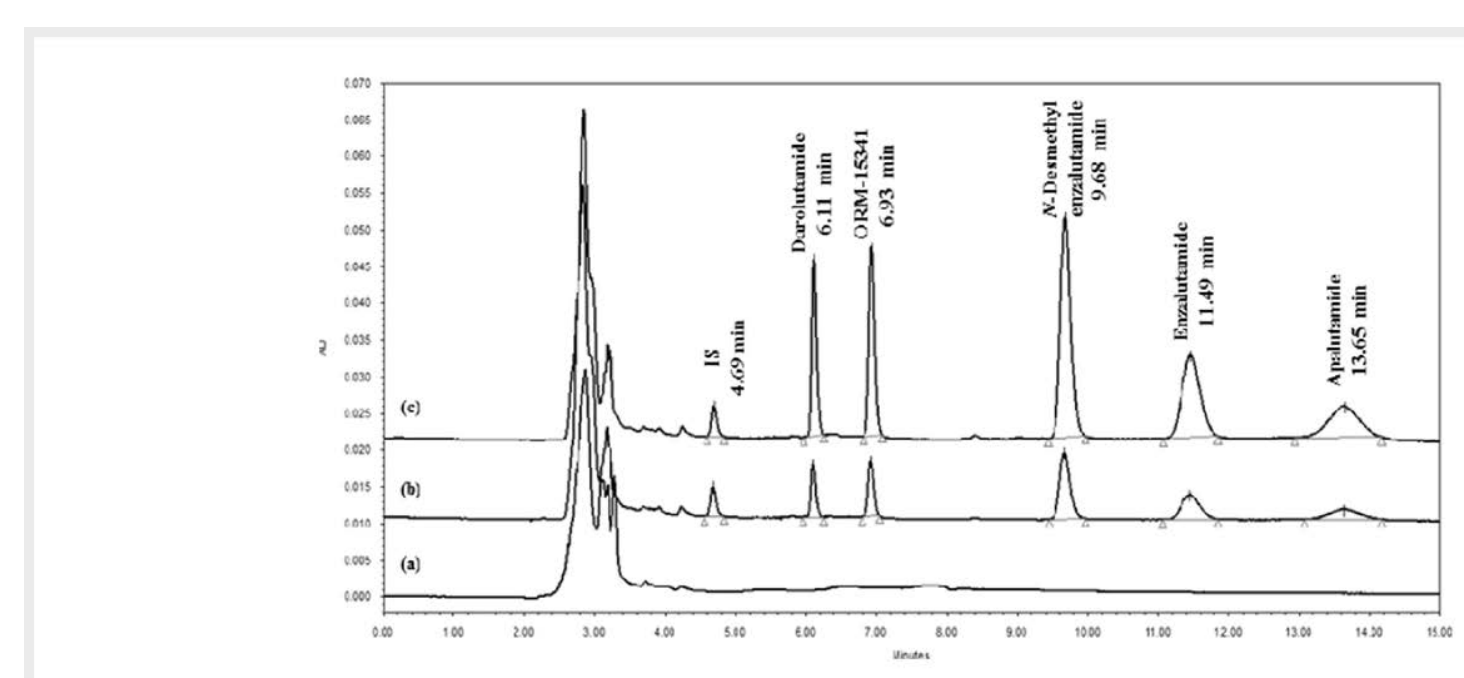

- Fig. 2 HPLC chromatograms of a $10 \mu \mathrm{L}$ injection of a mice blank plasma b blank mice plasma spiked with apalutamide, darolutamide, ORM15341 , enzalutamide and $N$-desmethylenzalutamide at LLOQ $(209 \mathrm{ng} / \mathrm{mL})$ along with $\mathrm{IS} \mathbf{c}$ an in vivo plasma sample collected from a mouse at $1.0 \mathrm{~h}$ time point following a cassette oral administration of apalutamide, darolutamide and enzalutamide. 
- Table 2 Intra- and inter-day precision and accuracy determination of apalutamide, darolutamide, ORM-15341, enzalutamide, $N$-desmethylenzalutamide quality controls in mice plasma.

\begin{tabular}{|c|c|c|c|c|c|}
\hline & $\begin{array}{l}\text { Concentration } \\
\text { spiked }(\mathrm{ng} / \mathrm{mL})\end{array}$ & $\begin{array}{l}\text { Intra-day } \\
\text { (\%RSD) }\end{array}$ & $\begin{array}{l}\text { Inter-day } \\
\text { (\%RSD) }\end{array}$ & $\begin{array}{l}\text { Accuracy } \\
\text { (\%RE) }\end{array}$ & $\begin{array}{l}\text { \%Recovery } \\
\text { (mean } \pm \text { SD) }\end{array}$ \\
\hline \multirow[t]{4}{*}{ Apalutamide } & 209 & 3.40 & 3.15 & 1.05 & - \\
\hline & 626 & 3.06 & 7.86 & 1.08 & $98.7 \pm 4.51$ \\
\hline & 2503 & 7.51 & 12.4 & 0.92 & $86.8 \pm 2.86$ \\
\hline & 4172 & 5.55 & 13.9 & 0.92 & $98.3 \pm 4.53$ \\
\hline \multirow[t]{4}{*}{ Darolutamide } & 209 & 8.88 & 8.22 & 0.88 & - \\
\hline & 626 & 1.30 & 4.21 & 1.01 & $101 \pm 4.27$ \\
\hline & 2503 & 1.43 & 2.67 & 0.96 & $93.1 \pm 4.41$ \\
\hline & 4172 & 0.61 & 2.06 & 0.99 & $98.4 \pm 1.24$ \\
\hline \multirow[t]{4}{*}{ ORM-15341 } & 209 & 1.13 & 1.04 & 1.01 & - \\
\hline & 626 & 2.48 & 3.48 & 1.00 & $98.0 \pm 1.91$ \\
\hline & 2503 & 1.12 & 3.66 & 0.97 & $94.0 \pm 3.68$ \\
\hline & 4172 & 0.56 & 1.93 & 1.01 & $101 \pm 0.78$ \\
\hline \multirow[t]{4}{*}{ Enzalutamide } & 209 & 4.06 & 3.76 & 1.02 & - \\
\hline & 626 & 1.78 & 4.02 & 1.04 & $99.3 \pm 4.12$ \\
\hline & 2503 & 1.64 & 3.90 & 0.96 & $95.6 \pm 4.14$ \\
\hline & 4172 & 1.16 & 2.99 & 0.99 & $100 \pm 1.02$ \\
\hline \multirow[t]{4}{*}{$\mathrm{N}$-Desmethylenzalutamide } & 209 & 3.40 & 3.15 & 1.04 & - \\
\hline & 626 & 0.62 & 2.81 & 1.01 & $103 \pm 4.65$ \\
\hline & 2503 & 1.81 & 3.69 & 0.96 & $96.2 \pm 3.29$ \\
\hline & 4172 & 1.48 & 2.78 & 0.99 & $97.7 \pm 2.31$ \\
\hline IS & 500 & - & - & - & $95.4 \pm 8.21$ \\
\hline
\end{tabular}

- Table 3 Stability data of apalutamide, darolutamide, ORM-15341, enzalutamide and N-desmethylenzalutamide quality controls in mice plasma.

\begin{tabular}{|c|c|c|c|c|c|c|c|c|c|}
\hline & \multirow{2}{*}{$\begin{array}{l}\text { Concentra- } \\
\text { tion spiked } \\
\text { (ng/mL) }\end{array}$} & \multicolumn{2}{|c|}{ Bench-top for $6 \mathrm{~h}$} & \multicolumn{2}{|c|}{$\begin{array}{l}\text { Long-term } 30 \text { days } \\
\text { at }-80^{\circ} \mathrm{C}\end{array}$} & \multicolumn{2}{|c|}{$\begin{array}{l}\text { Third freeze-thaw } \\
\text { cycle }\end{array}$} & \multicolumn{2}{|c|}{$\begin{array}{l}\text { Auto-sampler for } \\
24 \mathrm{~h}\end{array}$} \\
\hline & & \% RE & \%RSD & $\%$ RE & \%RSD & $\%$ RE & \%RSD & $\%$ RE & \%RSD \\
\hline \multirow[t]{2}{*}{ Apalutamide } & 626 & 0.98 & 7.27 & 1.06 & 3.61 & 1.03 & 3.27 & 0.94 & 8.86 \\
\hline & 4172 & 0.95 & 5.15 & 0.98 & 5.47 & 1.09 & 10.1 & 1.04 & 6.38 \\
\hline \multirow[t]{2}{*}{ Darolutamide } & 626 & 0.96 & 2.22 & 0.85 & 5.98 & 0.97 & 4.91 & 0.90 & 3.50 \\
\hline & 4172 & 1.03 & 1.87 & 0.92 & 1.47 & 1.02 & 5.48 & 1.04 & 1.03 \\
\hline \multirow[t]{2}{*}{ ORM-15341 } & 626 & 0.95 & 2.81 & 0.98 & 2.43 & 0.96 & 5.54 & 0.95 & 1.90 \\
\hline & 4172 & 1.05 & 2.84 & 1.08 & 2.03 & 1.03 & 5.12 & 1.03 & 1.01 \\
\hline \multirow[t]{2}{*}{ Enzalutamide } & 626 & 1.00 & 4.05 & 1.03 & 2.23 & 1.00 & 5.27 & 0.92 & 3.21 \\
\hline & 4172 & 1.04 & 3.19 & 0.88 & 2.07 & 0.99 & 4.83 & 0.97 & 0.94 \\
\hline \multirow[t]{2}{*}{$\mathrm{N}$-Desmethylenzalutamide } & 626 & 0.96 & 2.61 & 0.99 & 4.47 & 0.96 & 3.54 & 0.95 & 2.48 \\
\hline & 4172 & 1.03 & 2.33 & 1.12 & 1.74 & 1.01 & 5.03 & 1.01 & 0.92 \\
\hline
\end{tabular}

(released from darolutamide) are quantifiable up to $8 \mathrm{~h}$ and $12 \mathrm{~h}$ as illustrated in $>$ Fig. 3iii and $>$ Fig. 3iv, respectively. The pharmacokinetic parameters are compiled in $>$ Table 4. Both $\mathrm{AUC}_{(0-\infty)}$ (area under the curve from time 0 to infinity) and $C_{\max }$ (maximum concentration in plasma) were higher for ORM-15341 than darolutamide and this data is in agreement with data reported by us [17]. The $C_{\max }$ achieved at $0.5 \mathrm{~h}\left(\mathrm{~T}_{\max }\right)$ for both darolutamide and ORM15341. The half-life $\left(T_{1 / 2}\right)$ was found to be 4.77 and $8.53 \mathrm{~h}$ for darolutamide and ORM-15341, respectively. For enzalutamide and $\mathrm{N}$-desmethylenzalutamide the $\mathrm{AUC}_{(0-\infty)}$ and $\mathrm{C}_{\max }$ trend reported in humans [21] was seen in the present study. As apalutamide is structurally very close to enzalutamide the $A U C_{(0-\infty)}$ and $C_{\text {max }}$ are more or less similar to enzalutamide. Enzalutamide, $N$-desmethylenzalutamide and apalutamide have shown delayed $\mathrm{T}_{\max }(6-8 \mathrm{~h})$. Due to their persistence in plasma for $\geq 48 \mathrm{~h}$ and low clearance the halflife was found to be 13.2, 30.2 and $22.2 \mathrm{~h}$ for enzalutamide, $\mathrm{N}$-desmethylenzalutamide and apalutamide, respectively. In summary the validated method was sensitive enough to calculate the pharmacokinetics parameters of second generation non-steroidal antiandrogens along with their active metabolites. We believe that 

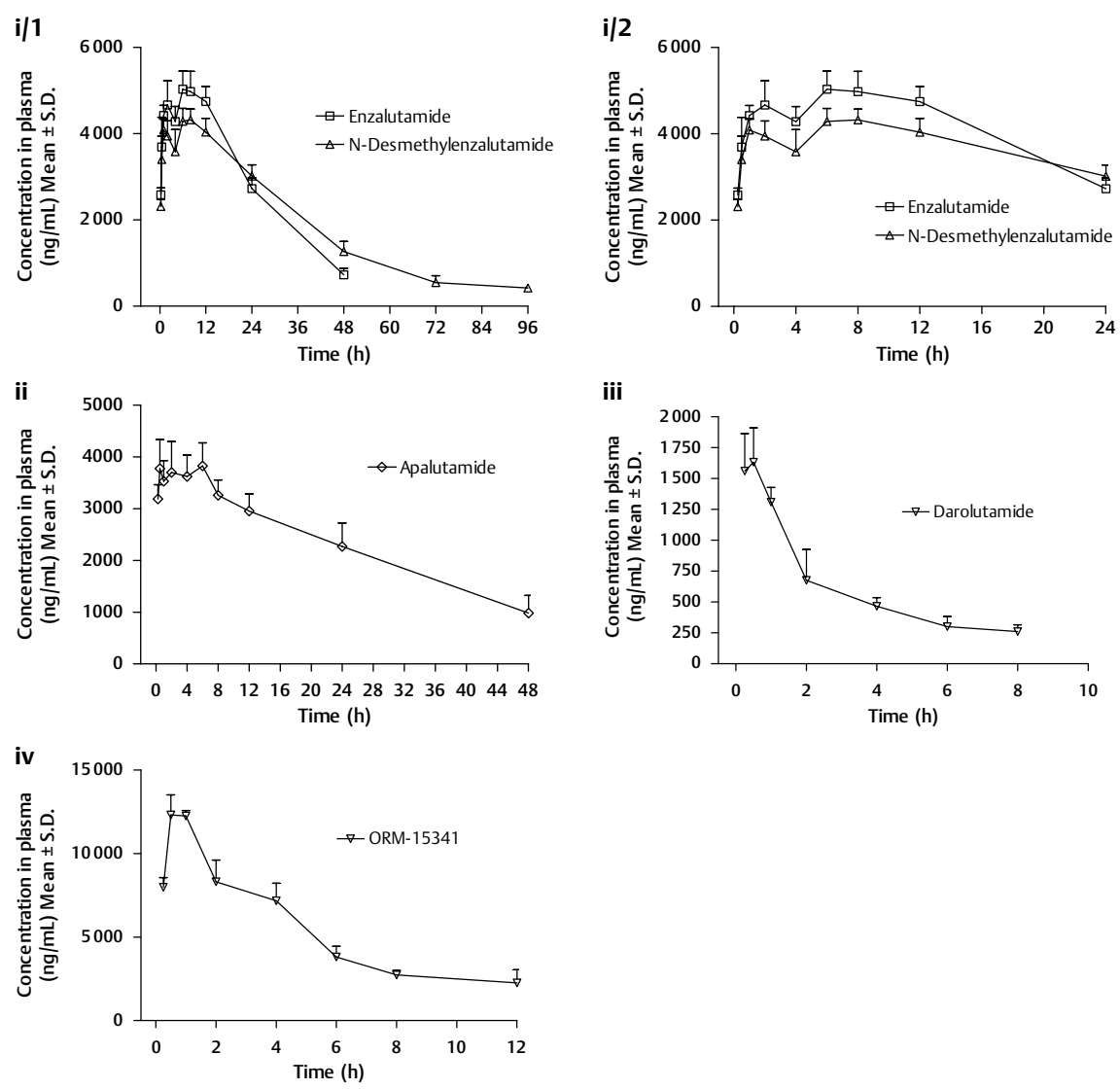

-Fig. 3 Mean plasma concentration vs. time profile for enzalutamide and $\mathrm{N}$-desmethylenzalutamide (released from enzalutamide) up to 48 and $96 \mathrm{~h}$, respectively in $\mathbf{i} / \mathbf{1}$ and up to $24 \mathrm{~h}$ in $\mathbf{i} / \mathbf{2}$; for apalutamide in ii; for darolutamide in iii and ORM-15341 (released from darolutamide) in iv in mice plasma following a cassette oral administration of apalutamide, darolutamide and enzalutamide to mice.

- Table 4 Pharmacokinetic parameters for apalutamide, darolutamide, ORM-15341, enzalutamide and N-desmethylenzalutamide following oral administration of apalutamide, darolutamide and enzalutamide to mice at $20 \mathrm{mg} / \mathrm{Kg}$.

\begin{tabular}{|l|l|l|l|l|}
\hline PK parameters & AUC $_{(\mathbf{0}-\infty)}(\boldsymbol{\mu} \mathbf{g} \times \mathbf{h} / \mathbf{m L})$ & $\mathbf{C}_{\max }(\boldsymbol{\mu g} / \mathbf{m L})$ & $\mathbf{T}_{\max }(\mathbf{h})$ & $\mathbf{T}_{\mathbf{1 / 2}}(\mathbf{h})$ \\
\hline Apalutamide & 142 & 3.82 & 6.00 & 22.2 \\
\hline Darolutamide & 6.57 & 1.63 & 0.50 & 4.77 \\
\hline ORM-15341 & 90.6 & 12.3 & 0.50 & 8.53 \\
\hline Enzalutamide & 155 & 5.03 & 6.00 & 13.2 \\
\hline N-Desmethylenzalutamide & 193 & 4.32 & 8.00 & 30.2 \\
\hline
\end{tabular}

the current method with little or no modifications can be extended to other pre-clinical species plasma matrix. The method can provide a lot of potential information to assist the researchers in deciding their approach for quantitation strategy towards pharmacokinetics and/or toxicokinetics in pre-clinical species and pharmacokinetics and/or therapeutic drug monitoring of second generation antiandrogens in clinic.

\section{Conclusion}

A simple reversed-phase HPLC method for determination of apalutamide, darolutamide, ORM-15341, enzalutamide and $\mathrm{N}$-des- methylenzalutamide in mice plasma has been developed and validated. The proposed method is highly specific, accurate, precise, sensitive and reproducible. The method requires less plasma sample for analysis and involves facile sample preparation. All the validation parameters were within the acceptable limits for bioanalytical method. This method has been successfully applied to a pharmacokinetic study in mice.

\section{Conflict of Interest}

All the authors have no conflict of interest to declare. 


\section{References}

[1] Siegel RL, Miller KD, Jemal A. Cancer statistics 2017. CA Cancer J Clin 2017; 67: 7-30

[2] Ryan C], Cheng ML. Abiraterone acetate for the treatment of prostate cancer. Expert Opin Pharmacother 2013; 14: 91-96

[3] Scher HI, Sawyers CL. Biology of progressive, castration-resistant prostate cancer: Directed therapies targeting the androgen-receptor signaling axis. J Clin Oncol 2005; 23: 8253-8261

[4] Scott LJ. Abiraterone acetate: A review in metastatic castration-resistant prostrate cancer. Drugs 2017; 77: 1565-1576

[5] Mullard A. 2012 FDA drug approvals. Nat Rev Drug Discov 2013; 12: 87-90

[6] Al-Salama ZT. Apalutamide: First global approval. Drugs 2018; 78: 699-705

[7] Moilanen AM, Riikonen R, Oksala R et al. Discovery of ODM-201, a new-generation androgen receptor inhibitor targeting resistance mechanisms to androgen signaling-directed prostate cancer therapies. Sci Rep 2017; 5: 12007

[8] Tran C, Ouk S, Clegg NJ et al. Development of a second-generation antiandrogen for treatment of advanced prostate cancer. Science 2009; 324: 787-790

[9] Clegg NJ, Wongvipat J, Joseph JD et al. ARN-509: A novel antiandrogen for prostate cancer treatment. Cancer Res 2012; 72: 1494-1503

[10] Erleada ${ }^{\mathrm{TM}}$. https://www.jnj.com/media-center/press-releases/ erleada-apalutamide-a-next-generation-androgen-receptor-inhibitorgranted-us-fda-approval-for-the-treatment-of-patients-with-non-metastatic-castration-resistant-prostate-cancer Accessed on 10 June 2018

[11] Semenas J, Dizeyi N, Persson JL. Enzalutamide as a second generation antiandrogen for treatment of advanced prostate cancer. Drug Des Devel Ther 2013; 7: 875-881

[12] Gibbons JA, Ouatas T, Krauwinkel W et al. Clinical pharmacokinetic studies of enzalutamide. Clin Pharmacokinet 2015; 54: 1043-1055

[13] Weiss ], Kocher J, Mueller $C$ et al. Impact of enzalutamide and its main metabolite $\mathrm{N}$-desmethylenzalutamide on pharmacokinetically important drug metabolizing enzymes and drug transporters. Biopharm Drug Dispos 2017; 38: 517-525

[14] Fizazi K, Massard C, James ND. ODM-201, a new generation androgen receptor inhibitor for castration-resistant prostate cancer: Preclinical and phase I data. Am Soc Clin Oncol J 2013; 31 (Suppl 6): Abstract 65

[15] Moilanen A, Riikonen R, Oksala R. ODM-201 - new generation antiandrogen with excellent antiandrogenic and antitumor activity in nonclinical models of CRPC. Eur J Cancer 2013; 49 (Suppl 2): Abstract 685

[16] Orion Pharma Clinical Study Code: 3104001/EN3386-201 (accessed on 10 July 2018)

[17] Dittakavi S, Nagasuri PKVSP, Sulochana SP et al. LC-MS/MS-ESI method for simultaneous quantification of darolutamide and its active metabolite, ORM-15341 in mice plasma and its application to a pharmacokinetic study. J Pharm Biomed Anal 2017; 145: 454-461

[18] Sulochana SP, Saini NK, Daram P et al. Validation of an LC-MS/MS method for simultaneous quantitation of enzalutamide, $\mathrm{N}$-desmethylenzalutamide, apalutamide, darolutamide and ORM-15341 in mice plasma and its application to a mice pharmacokinetic study. J Pharm Biomed Anal 2018; 156: 170-178

[19] Hallur G, Purra BR, Sulochana SP et al. Validation of an LC-ESI-MS/MS method for the determination of apalutamide, a novel non-steroidal anti-androgen in mice plasma and its application to a pharmacokinetic study in mice. J Pharm Biomed Anal 2018; 153: 260-266
[20] Song JH, Kim TH, Jung JW et al. Quantitative determination of enzalutamide, an anti-prostate cancer drug, in rat plasma using liquid chromatography-tandem mass spectrometry, and its application to a pharmacokinetic study. Biomed Chromatogr 2014; 28: 1112-1117

[21] Bennett S, Gibbons JA, Mol R et al. Validation of a method for quantifying enzalutamide and its major metabolites in human plasma by LC-MS/MS. Bioanalysis 2014; 6: 737-744

[22] Ohtsu Y, Thakker DR, Gibbons JA et al. Determination of the androgen receptor inhibitor enzalutamide and its metabolites in animal plasma and brain homogenates using LC-MS/MS and its application to pharmacokinetic studies. Chromatogr 2015; 36: 115-122

[23] Kim KP, Parise RA, Holleran JL et al. Simultaneous quantitation of abiraterone, enzalutamide, $\mathrm{N}$-desmethylenzalutamide, and bicalutamide in human plasma by LC-MS/MS. J Pharm Biomed Anal 2017; 138: 197-205

[24] van Nuland M, Hillebrand MJX, Rosing $\mathrm{H}$ et al. Development and validation of an LC-MS/MS method for the simultaneous quantification of abiraterone, enzalutamide, and their major metabolites in human plasma. Ther Drug Monit 2017; 39: 243-251

[25] Herbrink M, de Vries N, Rosing $\mathrm{H}$ et al. Development and validation of a liquid chromatography-tandem mass spectrometry analytical method for the therapeutic drug monitoring of eight novel anticancer drugs. Biomed Chromatogr 2017; 32: e4147

[26] Balaji N, Sulochana SP, Saini NK et al. Validation of a chiral LC-MS/ MS-ESI method for the simultaneous quantification of darolutamide diastereomers in mouse plasma and its application to a stereoselective pharmacokinetic study in mice. Biomed Chromatogr 2018; 32: e4173

[27] Balaji N, Sulochana SP, Saini NK et al. Validated chiral LC-ESI-MS/MS method for the simultaneous quantification of darolutamide diastereomers and its active metabolite in mice plasma: Application to a pharmacokinetic study. Drug Res 2018; 68: 615-624

[28] Saini NK, Sulochana SP, Zainuddin M et al. Development and validation of a novel method for simultaneous quantification of enzalutamide, darolutamide and their active metabolites in mice dried blood spots using LC-MS/MS: Application to pharmacokinetic study in mice. ADMET \& DMPK 2018; 6: 242-257

[29] Saini NK, Sulochana SP, Kiran V et al. A novel dried blood spot LC-MS/ MS method for the quantification of apalutamide in mice whole blood: Application to pharmacokinetic study in mice. Biomed Chromatogr 2018; 32: e4344

[30] Puszkiel A, Plé A, Huillard O et al. A simple HPLC-UV method for quantification of enzalutamide and its active metabolite $\mathrm{N}$-desmethyl enzalutamide in patients with metastatic castration-resistant prostate cancer. J Chromatogr B 2017; 1058: 102-107

[31] Rej RK, Acharyya RK, Nanda S. Asymmetric synthesis of dihydroartemisinic acid through intramolecular Stetter reaction. Tetrahedron 2016; 72: 4931-4937

[32] Pang X, Wang Y, Chen Y. Design, synthesis, and biological evaluation of deuterated apalutamide with improved pharmacokinetic profiles. Bioorganic \& Med Chem Lett 2017; 27: 2803-2806

[33] US DHHS, FDA, CDER, CVM, Guidance for Industry: Bioanalytical method validation, U.S. Department of Health and Human Services, Food and Drug Administration, Center for Drug Evaluation and Research (CDER), Center for Veterinary Medicine (CV), (2018), Rockville, MD, USA 